\title{
Cooperative Principle in English and Chinese Cultures
}

\author{
Yuanxiu He \\ School of Foreign Languages, Yangtze Normal University, Chongqing, China \\ Email:heyuanxiu2005@163.com
}

\begin{abstract}
Cooperative principle is believed to play a regulative role in English-speaking communication and any real or apparent violations of the maxims of cooperative principle will lead to what we call "conversational implicature", but this is not the case in Chinese culture. Chinese language users only conform to the Maxim of Relevance of the cooperative principle in a broad sense. Cooperative principle is quite limited to explain the natural Chinese expressions. Five causes that account for this are discussed in this paper.
\end{abstract}

Index Terms - cooperative principle, implicature, cultural differences

\section{CoOperative Principle in ENGLish ANd Chinese COMMUNicAtion}

The Cooperative principle (CP) is one of the widely known pragmatic principles which are used to interpret the literal sense and pragmatic force of utterances. However, it is not universal when different cultures are taken into account. When we take Chinese culture into account, for example, we find that Chinese people often do not conform to the maxims of $\mathrm{CP}$ beyond following the Maxim of Relevance in a broad sense. These language phenomena and the reasons for these which are concerning with the cultural aspects will be examined within this paper.

\section{A. Cooperative Principle in English Communication}

1. Grice's CP Theory

H.P.Grice in his famous paper "Logic and Conversation"(1975) suggests that there exists a set of maxims and sub-maxims that guide and constrain the conversation of rational people. He formulated his widely-known "Cooperative Principle", by which participants in conversation are expected to observe"Make your conversational contribution such as is required, at a stage at which it occurs, by the accepted purpose of direction of talk exchange in which you are engaged." (Grice, 1975, p.45)

This principle is associated with four constituent maxims, labeled as quantity, quality, relation and manner, each of which consists of one or more specific sub-maxims. Participants, in short, should speak "sincerely, relevantly and clearly, while providing sufficient information"(Grice, 1975, p.102). The Cooperative Principle is, in essence, a sort of tacit agreement between participants to work together to create a coherent and effective exchange. The maxims of CP are as follows:

The Cooperative Principle

Quantity: Give the right amount of information.

1. Make your contribution as informative as is required.

2. Do not make your contribution more informative than is required.

Quality: Try to make your contribution one that is true.

1. Do not say what you believe to be false.

2. Do not say that for which you lack adequate evidence.

Relation: Be relevant.

Manner: Be perspicuous.

1. Avoid obscurity of expression.

2. Avoid ambiguity.

3. Be brief (avoid unnecessary prolixity).

4. Be orderly.

(Adapted from Grice, 1975, p.41)

Grice assumes that the $\mathrm{CP}$ is always observed that any real or apparent violations of the maxims will lead to what he calls "conversational implicature",e.i. messages which are intended by the speaker but must be inferred by the hearer on the assumption that the speaker is cooperating in a specific manner. Grice's often quoted example is that of a recommendation letter written by a professor for a former student who has applied for a job. The letter read, "Dear Sir, Mr. X's command of English is excellent, and his attendance at tutorials has been regular." This, accordance to Grice, violates the maxim of quantity and leads to the implication that the professor does not think the student is suitable for the post and does not want to recommend him. The following sections present additional examples to illustrate how the maxims of $\mathrm{CP}$ are flouted or broken in interpersonal communication. 
1.1. The Breach of the Maxim of Quantity

(1) A: "Where does X live?"

B: "Somewhere in the suburb of the city."

B's answer obviously breaks the Maxim of Quantity. He does not tell A the exact place where X lives, and gives less information than A had hoped to hear. Supposing B knows where X lives, his answer implies that "I don't want to tell you."

(2) A: "We'll all miss Bill and Agatha, won't we?"

B: "Well, we'll all miss Bill." (qtd. Leech, 1983, p.50)

In (2), when A asks B to confirm A's opinion, B merely confirms part of it, and pointedly ignores the rest. As a result, B apparently fails to observe the Maxim of Quantity.

1.2. The Breach of the Maxim of Quality

(3) A: "Would you like to have a cup of coffee?"

B: "Sorry, I have an appointment right now."

Assuming B knows A clearly recognizes that B has no appointment at that time, then B's answer is a reflection of his desire to politely refuse A's invitation.

The breach of quality occurs not only when speakers employ implications, but also when they employ other traditional figures of speech, such as irony, metaphor, hyperbole, meiosis. Examples are as follows:

(4) "A triumph, a classic of this era." (Los Angeles Mirror) (Hyperbole)

(5) "He is an old fox, please do not play with him." (Metaphor)

(6) A: "We have met so many troubles today."

B: "That's right. We had a nice day." (Irony)

(7) A: "It is $38^{\circ} \mathrm{C}$ today. I'm sweating."

B: "Yes, it's a bit warm today." (Meiosis)

1.3. The Breach of the Maxim of Relevance

(8) A: "Can you answer the phone, darling?"

B: "I'm in the bath."

B's answer seems to have no relevance to A's question. But B has actually offered A the required information, and has obeyed the Quantity and Quality Maxims. B's answer implies that "I cannot answer the phone. You do it, darling." The following is an example of a breach of the Maxim of Relevance:

(9) A: "What do you think of my new dress?"

B: "It's interesting."

In (9), B is reluctant to show his true opinion, "I don't like it.", instead offering an irrelevant utterance.

1.4. The Breach of the Maxim of Manner

In English-speaking culture, flouting of the Maxim of Manner is not as common as flouting of the above maxims. When flouting the Maxim of Manner, people sometimes speak in a rather unnatural way to achieve special purposes.

(10) A: "Let's get the kids something."

B: "Okay, but I veto I-C-E-C-R-E-A-M.” (qtd.Levenson, 1983, p.104)

Here B ostentatiously violates the Maxim of Manner (be perspicuously) by spelling out the word ice-cream, and thereby conveys to A that B would rather not have the word "ice-cream" mentioned directly in the presence of the children, as its mention could possibly prompt them to demand some.

Like breaches of the Maxim of Quality, breaches of the Maxim of Manner often employ figures of speech, such as euphemism, pun, metonymy, synecdoche, antonomasia, and allusion, etc.

(11) He is a bit slow for his age. (Euphemism)

(12) "A sailor went to C-C-C (sea)

To see what he could C-C-C (see)

But all that he could C-C-C (see)

Was the bottom of the great blue C-C-C (sea)" (Pun)

(13) "When from the cradle to the grave I look,

Mine I conceive a melancholy book." (Geoge Crabbe: The Parish Register) (Metonymy)

(14) There is a mixture of the tiger and ape in the character of Frenchmen. (Synecdoche)

(15) "For decades the rest of America and the world expected the Big Apple to be the prime source of sustenance for the poor, homeless, huddled masses. " (Times) (Antonomasia)

(16) It (the book) is a vehicle of learning and enlightenment, an open sesame to countless joys and sorrows. (Allusion)

2. The Limitations of Grice's CP

Grice's CP can help to account for the relationship between sense and force of utterances, and to explain conversational implicatures, the inferences of which result from at least two distinct methods of communication: following or flouting the maxims. However, "the CP in itself cannot explain (i) why people are often so indirect in conveying what they mean; and (ii) what is the relationship exists between sense and force when non-declarative types of sentence are being considered." (Leech, 1983, p.80)Grice himself also admits that there are many other reasons and 
purposes for engaging in conversation beyond the effective exchange of information. For example, he puts forward the maxim, "Be Polite", which participants should observe in interaction, but does not go further to offer the issue of politeness.

\section{B. Cooperative Principle in Chinese Communication}

It has been argued that "the maxims of the CP are not universal to language, because there are linguistic communities to which not all of them apply" (Keenan, 1985, p.179). That is the case of Chinese language use. It must be noted that Chinese beyond following the Maxim of Relevance in a broad sense, most often do not conform to the maxims of CP. Differences in language use reflect different cultural values and the fact that Chinese people highly value indirect and ambiguous expressions for the sake of politeness, face, and other social factors.

1. The Breach of the Maxim of Quantity

(17)黛玉憋的脸上紫胀，便咬着牙用手指狠命的在他额夰上翟了一下，哼了一声，咬牙说道: “你这一一”刚说 了两字，便又叹了一口气，乃拿起手帕来擦眼泪。(The Red Mansion, p.238)

Too angry to speak, she (Lin Daiyu) fixed him (Bao-yu) with furious eyes until his cheeks were burning. Then, clenching her teeth, she stabbed with one finger at his forehead and said, "You..."

(Tr. The Yangs)

(18) 雇员：“大家提议放两天假。”

Employee: "We propose to have two days off."

经理: “哦?!”

Manager: "What?!"

雇员: “这个月的销量比上两月都好, 而且提前完成, 大家都觉得需要放松一下。”

Employee: "The sales this month are much better than during the last two months, and we have finished our work ahead of time."

经理: “哦。”

Manager: “Oh...”

雇员: “那是同意放了。太好了, 谢谢经理。”

Employee: "That's to say you agree? Oh, that's great. Thank you."

In (17), the utterance of "You..."obviously breaks the Maxim of Quantity. Lin Daiyu does not reveal Bao-yu her complex feelings clearly in a complete sentence, but uses just one word to give him a sense of what she means according to the context. In (18), the manager clearly breaks the Maxim of Quantity. But the conversation does not break down because the inadequate information given by the manager is enough to provide his listener with a sense of his full meaning.

2. The Breach of the Maxim of Quality

(19) 甲: “你干的真好!”

A: "You've done a great job."

乙: “不好, 不好。”

B: "No, not good, not good."

(20)甲: “你混得不错呀!”

A: "You've succeeded and gotten along well with the others."

乙: “哪里, 哪里。”(modest way of expression)

B: "No, no." (definitely negative expression)

(21) 甲: “时候不早了, 我们一起吃顿饭吧。”

A: "It's time to eat. Let's have an informal meal."

乙: “那多不好吆。”(acceptation)

B: "No. It's not grateful." (Refusal)

In order to politely avoid undesirable interpersonal communication, Chinese carefully consider the feelings of their listeners when giving "yes" or "no" answers; Americans, on the other hand, often use "yes" or "no" as a means of expressing their individual views without extensive consideration of the feelings of their listeners. "In other words," says Ringo Ma, “to say 'yes' for'no'or'no'for 'yes' is largely a reflection of the indirect approach to communication"'(1993, p.2-3). This contrary-to-face-value aspect of Chinese verbal language behavior can be confusing of course to English speakers. Consider the following example: "To communicate the request, 'Turn on the air-conditioner for me, please,' a Chinese may say: 'It's better in this room than outside the building', or 'It's ok, don't turn the air conditioner on.' Although the first statement is less contrary, both reflect the use of| no to say yes. In the first case, the statement suggests: 'It's still hot here, though it's cooler than outside. You should know that turning on the air conditioner will make me feel more comfortable.' The second statement implies, 'I say no, but you should know I really mean yes"” (William V. Ruth, 1989, p.174). Modesty is highly appreciated by Chinese people. Consequently, Chinese people usually sacrifice the maxim of quality in their interpersonal communication.

As in English conversation, Chinese language breaches in the Maxim of Quality can be accomplished using various figures of speech. Examples are as follows: 
(22) 烈祖: “外地都下雨了, 只是都城不下雨, 却是为何?”

Emperor Lie Zu asked, "It's raining in other parts, but the capital. Why?"

申渐道: “雨不敢入城, 是怕抽税而已。”《古今谭概: 微词》

Shen Jian replied, "The rain is hesitating because of the tax."

(Metaphor)

(23)“我可要给你提意见了, 你整日操劳, 把身体弄坏了, 是对革命的不负责任, 对我们单位也是一个损失嘛。” (Irony)

"I'd like to criticize you. You weakened your health by working day and night. This is not only irresponsible for our revolution, but also a loss for our dan wei (close community)."

We can find many more examples in our daily conversations. Supposing a person is late for his banquet, when he arrives at last, someone else attending the banquet may stand up immediately and say: “迟到了, 罚酒三杯。”This expression cannot be translated adequately into English, as it is impossible to convey fully the praising and politeness.

3. The Breach of the Maxim of Relevance

(24) 太宗问: “玄龄听说李伟任户部尚书后有什么表示?”

Tai Zong asked: "What does Xuan-ling think now that he knows $L i$ Wei has been appointed Minister of Revenue?"

来人说: “他只说·李伟长了好大一把胡须, ’再没说别的。” 《贞观政要. 择官》

The other man replied: "He only said, 'Li Wei has got a beautiful big beard', nothing else."

In order not to offend Tai Zong and $\mathrm{Li}$ Wei, Xuan-ling chose an irrelevant reply, the implication of which is that $\mathrm{Li}$ Wei is a nobody, his only commendable feature being his beautiful beard.

4. The Breach of the Maxim of Manner

Ringo Ma writes, "A major linguistic difference between Americans and Chinese lies in the use of direct and indirect language.” (1993, p.5) Chinese often use ambiguous expressions, some of which are culturally unique. Take, 反切（făn $q i e ̀$ ) and 歇后语 (xie hou yu) for example. Făn qiè is a traditional method used to indicate the pronunciation of a Chinese character by using two other Chinese characters, the first having the same consonant as the given character and the second having the same vowel (with or without final nasal)and tone. For example pronunciation of 同(tóng) is indicated as 徒红切(túhongqiè), meaning a combination of the consonant “ $t$ " from 徒 (tú) and the vowel plus nazal (óng) from 红. Frequently, educated Chinese also use this figure of speech to criticize or make fun of others or for other purposes, i.e. in spying field.

Xie hou уи (two-part allegorical saying) is a vivid and quite common linguistic method used in China. Examples are as follows:

(25)泥菩萨过河 一自身难保。

(A clay idol fording a river_ hardly able to save himself, let alone assist anyone else)

(26)偷来的锣鼓——打不得。

(The steeled gong and drum_— cannot be hit)

(27)外甥打灯笼一一照舅(旧) （back in the old nut）

Because Chinese prefer indirect and implicit expressions in interpersonal communication, breaches of the Maxim of Manner are as popular as above breaches.

According to Grice's CP theory, people generally speak sincerely, relevantly and clearly, while providing sufficient information; when people break maxims, there should be an implicature. But examples (17), (18), (19), (20), and (21), have no implications; they are simply natural expressions. Therefore, Grice's CP theory is not convincing in explaining the uses of Chinese language. Strictly speaking, Chinese do not necessarily comply with the maxims of CP, beyond compliance with the Maxim of Relevance in a broad sense. How is it that Chinese can be said to comply with the Maxim of Relevance in a broad sense? One reason is that "in a broader sense, an utterance can be relevant to a speech situation if the utterance can be interpreted as contributing to the conversational goal(s)" (Leech, 1983, p. 94).Smith and Wilson (1979, p.177) also give an informal definition of relevance as "A remark $P$ is relevant to another remark $Q$ if $P$ and $Q$, together with background knowledge, yield new information not derivable from either $P$ or $Q$, together with background knowledge, alone." A second reason is that the process of communication is ultimately a matter of guesswork, or to use a more dignified term, "hypothesis formation" (Sperb \& Wilson, 1986, p.24).Consequently, whatever a person says can be considered to be relevant to the communication, on the assumption that the participants are cooperating toward social or personal goals.

\section{CP ANd CUltural DifFerences}

\section{A. $\quad C P$ and English Culture}

The Halls maintain that cultural communication generally can be compared on a scale of high to low context, and define these two terms in the following manner:

High context (HC) communication or message is one in which most of the information is already in the person, while 
very little is in the coded, explicitly transmitted part of the message. A low context (LC) communication is just the opposite; i.e. the mass of the information is vested in the explicit code. (1990, p.79)

In low-context culture, the populations are less homogeneous and therefore tend to compartmentalize interpersonal contacts. The Halls argue that this lack of a large pool of common experience means that "each time they interact with others individuals need detailed background information" (1976, p.7). In low-context culture, the verbal message contains most of the information, while very little is embedded in the participants' conversational context. Individuals living in low-context cultures expect conversational messages to be detailed, clear-cut, and definite. If there is not enough data, or if the point is not readily apparent, members of low-context cultures often ask questions. They feel uncomfortable with the vagueness and ambiguity often associated with limited data. Hall notes that English-speaking culture is a low-context culture. Another reason why English-speakers value direct and clear expressions is closely connected with the concept of individualism. Individualism encourages people to express themselves freely and frankly.

Through above analysis, we have founded the cultural source on which Grice based his proposal of CP and of the conversational implicature for the English language use. In another word, Grice's CP theory and the conversational implicature is to some degrees explanatory for the English language use because English-speaking culture is low-context culture, sincere, clear, and relevant utterances loaded with adequate information are appreciated.

\section{B. $\quad C P$ and Chinese Culture}

Chinese people do not necessarily conform to the maxims of $\mathrm{CP}$ as a result of the impact of five cultural aspects. First, in contrast to the low-context culture of most English-speakers, Chinese possess a high-context culture. The Halls (1990, p.6) note that in high-context cultures, people are frequently homogenous in regard to experiences, information networks, and other social aspects. High-context cultures, as a result of their long tradition and history, change very little over time, and consistent messages have produced consistent responses to the environment. The Halls (1976) also indicate that in high-context cultures, most of the information lies either in the setting or in the people who engage in conversation. Little information is actually contained in the verbal message. "As a result," the Halls writes "for most normal transactions in daily life individuals do not require, nor do they expect, much in-depth background information"(1990, p.17).

Furthermore, people in high-context cultures tend to be more aware of their surroundings and their environment, and, as a result, do not rely on verbal communication as their primary information channel. In reference to this phenomenon, Chinese language contains the phrase, “mei mu chuan qing(眉目传情), ”which means "being able to communicate with the eyes." In high-context cultures, the wealth of information available in the surrounding environment makes it unnecessary for people to verbalize everything; in other words, because the message is conveyed by the context, a great deal of information can be sensed and thereafter, does not have to be explained with words. People in HC cultures also believe that silence often sends a better message than words. Consider the Chinese proverb "silence speaks more than words(此时无声胜有声)" and the following criticism of people who talk a lot “empty cans clatter the loudest(半壸 水响叮当).”

Second, the hierarchical social structure developed over 5,000 years of civilization has had a great impact on language use. According to sociological research, the more power and higher position one possesses, the quantity of information he gives is much less or more when interact with others. As a result, the distribution of quantity is uneven. Conversation (18) is a case in point.

Third, Chinese language use is heavily governed by traditional conventions and rules of morality. Throughout history, language use and verbal activity have been heavily influenced by a "Chinese Bible" known as “中庸” (Doctrines of Mean ). Zhong Yong is a classic Confucian work, separated from $L i J i$ “礼记”(On $L i$ )during the time of the South and North Dynasties. According to the explanation of ZhuXi (1987, p.25): “不偏之谓中, 不易之谓庸。中者, 天下之正 道。庸者, 天下之定理。” The use of “Zhong” reflects the argument that a person should not go to extremes, while "Yong" refers the natural rules of society. One cannot speak sincerely, clearly, while providing sufficient information, because it is thought that to do so is in violation of the natural rules of Chinese culture.

Fourth, courtesy, etiquette and face considerations are of great importance in China. George Yule (1985, p.190) writes, "Culture determines or constrains the use of language." Hackett (1963, p.14)also notes that "speech is a form of social identity and is used, consciously or unconsciously, to indicate membership of different social groups or different speech communities." Therefore, Chinese frequently break the Maxim of Quality for the sake of face or politeness considerations.(19), (20), (21) are good examples.

The final reason concerns the structure of Chinese language itself. The structure of Chinese language is quite loosely composed of meaningful separate characters within less cohesive words. This language structure promotes ambiguity. Here is example: (“父在母先亡”). This sentence can be interpreted in two ways: (a) “父——在母先——亡”（Father died before mother. ),(b)“父在, 母先亡”(Father is still living, but mother died.); Which way is the correct interpretation depends on the speaker's punctuation.

To sum up, the Chinese mode of communication usually violates the Cooperative Principle and tends to be indirect and implicit. 


\section{SUMMARY}

While Grice's CP theory can be used to explain a certain limited amount about English language use, it cannot be effectively used to explain Chinese language use at all. Owing to the high context culture, convention and for the sake of politeness, Chinese language users only conform to the Maxim of Relevance in a broad sense.

\section{REFERENCES}

[1] Grice, H. Paul. (1975). Logic and conversation. In Peter Cole and Jerry Morgan (ed.) Syntax and Semantics. Volume 3: Speech Acts. New York: Academic Press, 41-102.

[2] Hall, E. T. (1976). Beyond Culture. New York: Anchor Press.

[3] Hall, E. T. \& M. R. Hall. (1990). Understanding Cultural Differences: German, French and Americans. Yarmouth, ME: International Press.

[4] Hochett, C.F. (1963).The problem of universals in language. In J. H. Greenberg(ed.) Universals of Language. M.I. T. Press, 14.

[5] Keenan, Edward L. (1985). Passive in the World's Language. In Timothy Shopen (ed.) Language Typology and Syntactic Description, Vol. 1. Cambridge: Cambridge University Press, 179.

[6] Leech, G. (1983). Principles or Pragmatics. London: Longman.

[7] Levinson, Stephen C. (1983). Pragmatics. Cambridge: CUP.

[8] Ringo, Ma. (1993).Saying 'yes' for 'no' and 'no' for 'yes': a Chinese rule. (Paper presented at the Annual Meeting of the Speech Communication Association (79th, Miami Beach, FL, November 18-21), 2-5.

[9] Smith, N. \& D. Wilson. (1979). Modern Linguistics: The Results of Chomsky's Revolution. Harmondsworth: Penguin.

[10] Sperb, D. \& D. Wilson. (1986). Relevance: Communication and Cognition. Basil: Blackwell Ltd.

[11] William V. Ruth. (1989). International Handbook of Corporate Communication. Jefferson, NC: McFarland.

[12] Zhu Xi. (1987).Complied Notes on the Four Books. Changsha: Yuelu Publishing House.

Yuanxiu He was born in Chongqing, China in 1966. She received her M.A degree in linguistics from South-West University, China in 2003.

She is currently an associate professor in the School of Foreign Languages, Yangtze Normal University, Chongqing, China.

Ms. He is a member of the Translators' Association of Chongqing. 